\title{
Effect of soil water saturation on slope stability: Tomsk case study
}

\author{
Natalia Brakorenko ${ }^{1}$, Anna Leonova ${ }^{1, *}$, and Aleksey Nikitenkov ${ }^{1}$ \\ ${ }^{1}$ Tomsk Polytechnic University, Geology department, 634050 \\ Lenina Avenue 30, Tomsk, Russia
}

\begin{abstract}
We investigate in this article the impact of soil water saturation on the slope stability, using a site in Tomsk city as a case study. The dependency of the shear strength parameters of soil on the degree of soil water saturation has been demonstrated. The paper also provides equations for the calculation of slope stability coefficient under different values of soil water saturation.
\end{abstract}

\section{Introduction}

Subsoil water is one of the factors influencing the condition of slope stability. The water acts as an ascending force on the soils and rocks constituting the slope, thus changing the force of gravity. While saturating soil, water changes its physico-mechanical properties, in particular shear strength characteristics by reducing the value of shear resistance. In addition, being a lubricant, water wets possible planes and reduces friction between them. It ascends a soil matrix, and reduces normal tensions $\sigma$ in the shift surface due to pore pressure, which can almost eliminate the internal friction in soil [1]. In course of construction, water can enter the soil due to natural processes, however, in most cases, water infiltration results from technogenic waterlogging caused by the damming effect and sub utility leaks that are on the increase in urban areas. Typically, in course of site investigation, the values of stability coefficients (cohesion, the angle of internal friction, bulk density) are determined for natural water content, that is the water content measured at the time of investigation. These parameters are rarely determined under the condition of high water saturation.

Thus, the research aims to determine the correlation between the soil shear strength parameters and the degree of soil water saturation, and to forecast slope stability with various degrees of water saturation.

\section{Materials and methods}

The research work is based on the investigation data [2] and the data obtained from laboratory tests on soil properties conducted for this studt. The moisture content was determined by the oven-drying method according to [2]; the bulk density of soil was determined via a volumetric ring (core cutter method), in accordance with [2]; A Litvinov field laboratory was used to determine the angle of internal friction and cohesion. The tests were conducted in research laboratory "Ground Science and Soil Mechanics"). Statistica and MS Excel software were used for data processing.

\footnotetext{
*Corresponding author: avleonova@ rambler.ru
} 


\section{Results}

More than 330 core samples were collected at the site situated in the eastern part of Tomsk, district № 9, residential area "Vostochny" (Fig. 1), to study the correlation between the soil shear strength properties and degree of water saturation. The area is confined to the surface of Tom'-Yajsky watershed divide in terms of geomorphology (laQII-III).

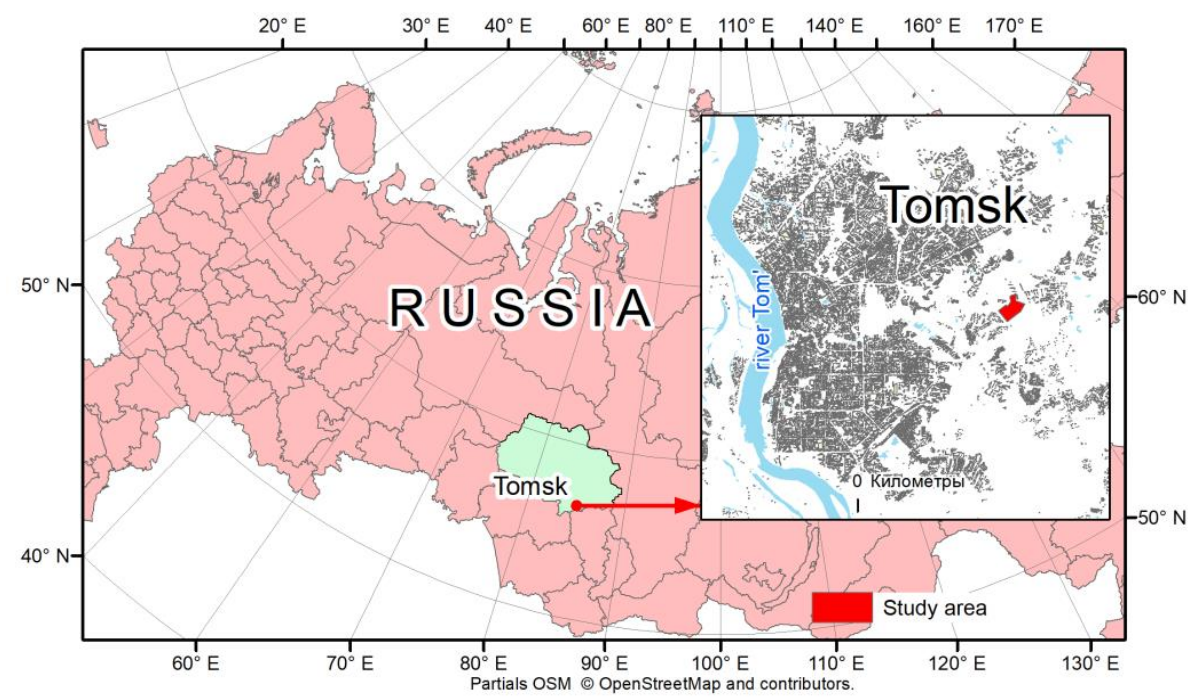

Fig. 1. Location map and scheme of the studied area.

The altitude of the area under investigation changes from $132 \mathrm{~m}$ to $161 \mathrm{~m}$ above sea level, which makes $29 \mathrm{~m}$ of difference in elevation. The surface run-off moves northward. The geologic and lithologic cross-sections of the studied area are as follows: modern biogenetic sediments (bQIV) make a top soil stratum from the surface down to 0.2-0.6 m depth. Hereafter, the penetrated thickness of $30 \mathrm{~m}$ exhibits Middle and Upper Quaternary deposits of the watershed divide (laQII-III) - these are brownish-gray clays of solid or semi-solid consistency, brownish-gray clay loams ranging from solid to viscous-liquid states, grayish-brown viscous-liquid sand clays, and medium-grained sand; Lower and Upper Oligocene lacustrine-alluvial deposits of Novomikhailovskaya suite (P2-3nm) they are represented by grayish-blue clays of solid and semisolid consistency. Table 1 provides the generalized values of physic-mechanical parameters of the soils.

Table 1. Values of ground properties.

\begin{tabular}{|c|c|c|c|c|c|c|c|c|c|c|c|}
\hline $\begin{array}{c}\rho_{\mathrm{s}}, \\
\mathrm{g} / \mathrm{cm}^{3}\end{array}$ & $\rho, \mathrm{g} / \mathrm{cm}^{3}$ & $\begin{array}{c}\rho_{\mathrm{d}}, \\
\mathrm{c} / \mathrm{cm}^{3}\end{array}$ & $\begin{array}{l}\mathrm{e}, \text { unit } \\
\text { fraction }\end{array}$ & $\mathrm{W} \%$ & $\mathrm{~W}_{\mathrm{L}}, \%$ & $\mathrm{~W}_{\mathrm{P}}, \%$ & $\mathrm{I}_{\mathrm{P}}, \%$ & $\begin{array}{l}\mathrm{S}_{\mathrm{r}} \text {, unit } \\
\text { fraction }\end{array}$ & $\varphi$, deg. & $\mathrm{C}, \mathrm{kp} / \mathrm{cm}^{2}$ & $\mathrm{E}, \mathrm{MPa}$ \\
\hline \multicolumn{12}{|c|}{ (minimum - maximum) / average } \\
\hline \multicolumn{12}{|c|}{ Clay loams } \\
\hline$\frac{2.55-}{2.74}$ & $\frac{1.32-}{2.13}$ & $\frac{0.96-}{1.83}$ & $\frac{0.48-}{1.66}$ & $\underline{12.5-}$ & $\frac{21.5-}{46.1}$ & $\frac{14.2-}{32.7}$ & $\frac{7.1-}{17.0}$ & $\frac{0.58-}{1.11}$ & $\underline{14-27}$ & $\underline{0.13-0.71}$ & $16-156$ \\
\hline 2.70 & 2.01 & 1.64 & 0.66 & 22.93 & 29.69 & 19.11 & 10.59 & 0.94 & 20.51 & 0.30 & 54.80 \\
\hline \multicolumn{12}{|c|}{ sandy clays } \\
\hline$\frac{2.66-}{270}$ & $\frac{1.73-}{212}$ & $\frac{1.48-}{1.84}$ & $0.46-$ & $5.6-26.1$ & $15.2-26$ & $\frac{12.5-}{203}$ & $2.2-6.9$ & $\frac{0.33-}{1.05}$ & 17-31 & $\underline{0.07-0.31}$ & $\frac{0,01-}{160}$ \\
\hline$\frac{2.10}{2.68}$ & $\frac{2.12}{1.95}$ & $\frac{1.04}{1.67}$ & $\frac{0.02}{0.61}$ & 17.04 & 20.37 & 15.73 & 4.62 & 0.75 & 22.86 & 0.20 & 67.83 \\
\hline
\end{tabular}


Figures 2 and 3 show the diagrams representing dependency of strength properties of clay loam on water content. These figures show a regular reduction in both cohesion and the angle of internal friction with the increase in water content.

The slope stability coefficient was calculated on path with greatest ground slope. The method of curvilinear sliding surface that is very similar to a logarithmic spiral was used to assess the slope stability considering geology aspect, slope morphology, and soil composition and condition. The method is used to calculate the stability slopes and back slopes made of sand-and-clay poorly lithified soils without softening planes sliding towards the slope direction. In this case, consequent landslides with circular cylindrical or of curvilinear sliding surfaces can occur [3].

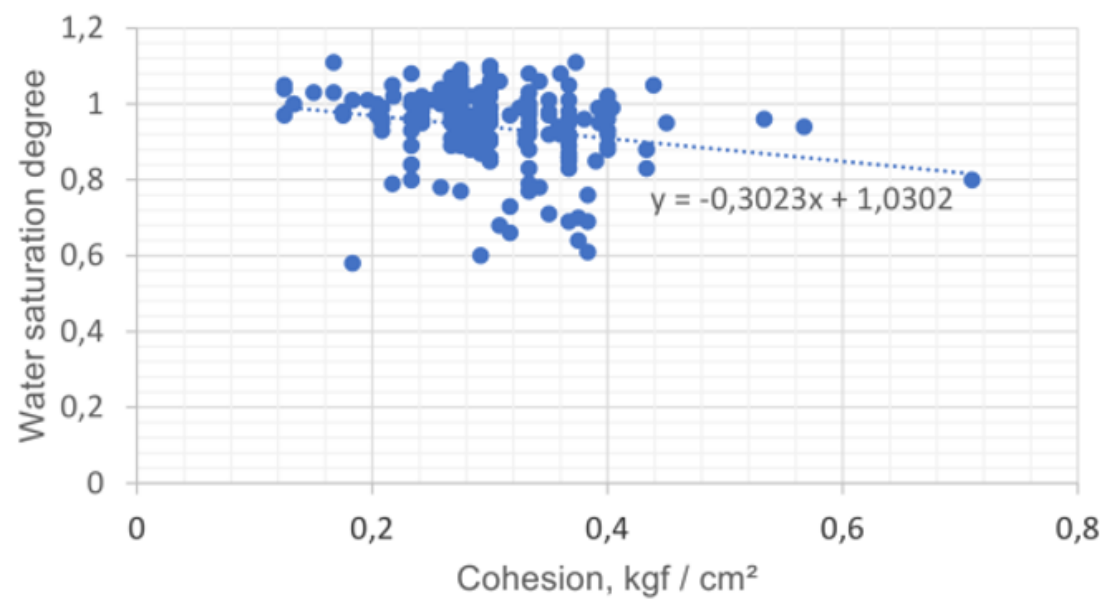

Fig. 2. Dependence of clay loam cohesion on the degree of water saturation.

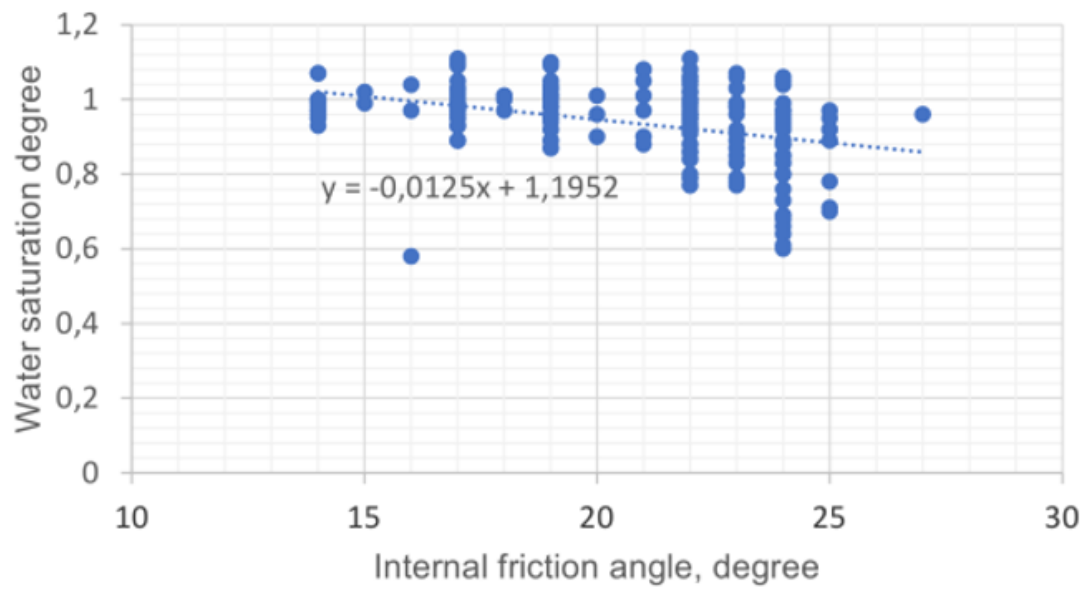

Fig. 3. Dependence of clay loam internal friction angle on the degree of water saturation.

Results proved that the shear strength parameters of soil depend on water content. Thus, while calculating the slope stability coefficient, it is necessary to take into account the most unfavorable soil condition. Therefore, the calculation was based on the values of the shear strength parameters for both natural degree of water content and full water saturation. 
Table 2. Data for calculating slope stability coefficient.

\begin{tabular}{|c|c|c|c|c|c|c|c|}
\hline \multirow[t]{2}{*}{ Layer } & \multirow[t]{2}{*}{$\begin{array}{l}\text { Thickness, } \\
\text { m } \\
\text { (h) }\end{array}$} & \multicolumn{3}{|c|}{$\begin{array}{c}\text { Predicted performance of soils } \\
\text { with natural degree of water } \\
\text { content }\end{array}$} & \multicolumn{3}{|c|}{$\begin{array}{l}\text { Predicted performance of } \\
\text { fully saturated soils }\end{array}$} \\
\hline & & $\begin{array}{c}\gamma, \\
\mathrm{kN} / \mathbf{m}^{3}\end{array}$ & $\varphi$, deg. & $\mathrm{C}, \mathbf{K P a}$ & $\begin{array}{c}\gamma, \\
\mathbf{k N} / \mathbf{m}^{3}\end{array}$ & $\begin{array}{l}\varphi, \\
\text { deg. }\end{array}$ & $\mathbf{C}, \mathbf{K P a}$ \\
\hline \multicolumn{8}{|c|}{ well 1} \\
\hline $\begin{array}{l}\text { Organic clay } \\
\text { soft-firm }\end{array}$ & 3.8 & 19.6 & 20 & 20.0 & 19.6 & 17 & 17.1 \\
\hline $\begin{array}{l}\text { Organic clay } \\
\text { very soft-firm }\end{array}$ & 3.5 & 20.1 & 15 & 12.5 & 20.1 & 14 & 12.1 \\
\hline $\begin{array}{l}\text { Organic clay } \\
\text { soft-firm }\end{array}$ & 1.2 & 19.6 & 20 & 20.0 & 19.6 & 17 & 17.1 \\
\hline $\begin{array}{l}\text { Organic clay } \\
\text { very soft-firm }\end{array}$ & 1.5 & 20.1 & 15 & 12.5 & 20.1 & 14 & 12.1 \\
\hline $\begin{array}{l}\text { Organic clay } \\
\text { soft-firm }\end{array}$ & 1.2 & 19.6 & 20 & 20.0 & 19.6 & 17 & 17.1 \\
\hline Medium sand & 2.0 & 18.7 & 25 & 0 & 18.7 & 25 & 0 \\
\hline $\begin{array}{l}\text { Organic clay } \\
\text { stiff }\end{array}$ & 0.7 & 19.4 & 21 & 51.6 & 19.4 & 18 & 39.2 \\
\hline $\begin{array}{l}\text { Organic clay } \\
\text { soft-firm }\end{array}$ & 3.7 & 19.6 & 20 & 20.0 & 19.6 & 17 & 17.1 \\
\hline $\begin{array}{l}\text { Organic clay } \\
\text { stiff }\end{array}$ & 1.6 & 19.4 & 21 & 51.6 & 19.4 & 18 & 39.2 \\
\hline $\begin{array}{l}\text { Organic clay } \\
\text { soft-firm }\end{array}$ & 1.4 & 19.6 & 20 & 20.0 & 19.6 & 17 & 17.1 \\
\hline $\begin{array}{l}\text { Organic clay } \\
\text { stiff }\end{array}$ & 7.0 & 19.4 & 21 & 51.6 & 19.4 & 18 & 39.2 \\
\hline $\begin{array}{c}\text { Organic clay } \\
\text { soft-firm }\end{array}$ & 0.8 & 19.6 & 20 & 20.0 & 19.6 & 17 & 17.1 \\
\hline \multicolumn{8}{|c|}{ well 2} \\
\hline $\begin{array}{c}\text { Organic clay } \\
\text { soft-firm }\end{array}$ & 7.6 & 19.6 & 20 & 20.0 & 19.6 & 17 & 17.1 \\
\hline $\begin{array}{l}\text { Organic clay } \\
\text { very soft-firm }\end{array}$ & 12.6 & 20.1 & 15 & 12.5 & 20.1 & 14 & 12.1 \\
\hline $\begin{array}{l}\text { Organic clay } \\
\text { very stiff }\end{array}$ & 1.1 & 20.1 & 22 & 29.3 & 20.1 & 19 & 18 \\
\hline $\begin{array}{l}\text { Organic clay } \\
\text { soft-firm }\end{array}$ & 1.4 & 19.6 & 20 & 20.0 & 19.6 & 17 & 17.1 \\
\hline $\begin{array}{l}\text { Organic clay } \\
\text { very soft-firm }\end{array}$ & 1.6 & 20.1 & 15 & 12.5 & 20.1 & 14 & 12.1 \\
\hline $\begin{array}{l}\text { Organic clay } \\
\text { very stiff }\end{array}$ & 1.3 & 20.1 & 22 & 23.9 & 20.1 & 19 & 18.0 \\
\hline $\begin{array}{c}\text { Organic clay } \\
\text { stiff }\end{array}$ & 4.4 & 19.4 & 21 & 51.6 & 19.4 & 18 & 39.2 \\
\hline
\end{tabular}

The method of curvilinear sliding surface that is very similar to a logarithmic spiral is based on the limit equilibrium theory. To determine the most dangerous inclined plane (with the minimum stability coefficient) it is necessary to determine the value of radius $r_{0}$ and the values of varying radii $r_{i}$, projected at an angle $\theta$ to the slope surface. 


$$
\mathrm{r}_{0}=\mathrm{H} \cdot \operatorname{ctg} \alpha[\operatorname{tg} \alpha+\operatorname{tg}(45+\varphi / 2)]-\mathrm{H}_{90} / \cos \alpha[\operatorname{tg} \alpha+\operatorname{tg}(45+\varphi / 2)]-\mathrm{e}-(90-\alpha) \cdot \varepsilon
$$

where $\mathrm{H}_{90}$ - value of vertical part of a slope; $\mathrm{H}_{90}=\cdot \operatorname{tg}(45+\varphi / 2) ; \mathrm{H}-$ slope height, $\mathrm{m} ; \alpha$ - angle of slope, deg; $\varphi$ - weighted average value of the angle of internal friction, deg; $\varepsilon=45-\varphi / 2$.

The values of varying radii are calculated according to the formula:

$$
\mathrm{r}_{\mathrm{i}}=\mathrm{r}_{0} \cdot \exp (-\theta \cdot \operatorname{ctg} \varepsilon)
$$

We obtain the estimate inclined plane with the minimum stability coefficient by linking the segments equal to the values of the varying radii.

The width of landslide prism (a) is calculated according to the equation:

$$
a_{i}=2 \cdot\left(r_{0} \cdot \cos \alpha-H \cdot \operatorname{ctg} \alpha\right)
$$

After determining the position of the estimate inclined slope, the selected failure prism is divided into separate blocks with the curvilinear sliding surface being regarded as a flat surface within their limits.

Weight $(\mathrm{G})$, normal weight component $(\mathrm{N})$ and tangential weight component $(\mathrm{T})$ for each selected blocks are calculated.

$$
\mathrm{N}_{\mathrm{i}}=\mathrm{G}_{\mathrm{i}} \cdot \cos \alpha_{\mathrm{i}} ; \quad \mathrm{Ti}=\mathrm{G}_{\mathrm{i}} \cdot \sin \alpha_{\mathrm{i}}
$$

The stability coefficient $\left(\mathrm{K}_{\mathrm{st}}\right)$ is calculated by algebraic addition of the forces. The stability coefficient calculation is based on relation of shear stress and shear strength. The shear strength is conditioned by strength parameters of a soil mass $(\varphi, c)$, while the tangential components of the weight of the blocks $(T=G \cdot \sin \alpha)$ cause shear forces. If the slope of the inclined plane is in opposite direction to the direction of the general shift of the soil mass, the tangential component is regarded as shear strength.

$$
\mathrm{K}_{\mathrm{st}}=\mathrm{M}_{\mathrm{rel}} / \mathrm{M}_{\text {shift }}=\Sigma \mathrm{G}_{\mathrm{i}} \cdot \cos \alpha_{\mathrm{i}} \cdot \operatorname{tg} \varphi+\Sigma \mathrm{l}_{\mathrm{i}} \cdot \mathrm{C}_{\mathrm{i}}+\Sigma \mathrm{G} \cdot \sin \alpha^{\prime}\left(\Sigma \mathrm{G}_{\mathrm{i}} \cdot \sin \alpha\right)
$$

where: $\mathrm{G}_{\mathrm{i}}$ - weight of a block, $\mathrm{\kappa N} / \mathrm{m} ; \alpha_{\mathrm{i}}$ - slope angle of the incline plane, deg.; $\varphi$ - angle of internal friction over an inclined plane, deg.; $l_{i}$ - distance of the inclined plane, $\mathrm{m}$; $\mathrm{C}$ - specific cohesion, $\mathrm{KPa}$.

The calculations found the following slope stability coefficients:

For natural degree of water content: $K_{\text {st }}=2.70$

For water saturated condition: $\mathrm{K}_{\mathrm{st}}=2.41$

Thus, the shear strength parameters of the soil with natural and high water content have been studied. These data are used to calculate the slope stability coefficients. Therefore, the values of water content influence the slope stability coefficients and account for the difference in their values reaching $\sim 10 \%$. The data obtained here can be applied in geological hazards zoning in terms of technogenic waterlogging.

\section{References}

1. L.K. Ginzburg, Recommendations about the choice of methods of calculation of coefficient of stability of a slope and landslide pressure (CNTI, 1986) (In Russian)

2. GOST 5180-2015 Soils. Laboratory Methods for Determination of Physical Characteristics (Standartinform, Moscow, 2016).

3. G.K. Bondarik, V.V. Pendin, and L.A. Yarg, Engineering Geodynamic (Publishing house KDU LLC, 2009) (In Russian) 